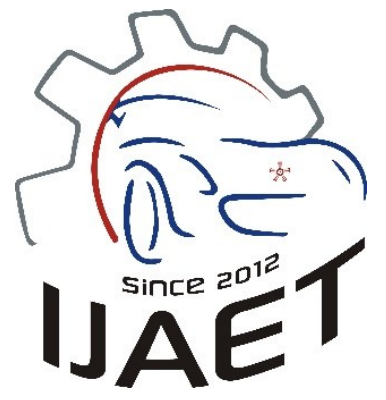

e-ISSN: 2146 - 9067

International Journal of Automotive

Engineering and Technologies

journal homepage:

https://dergipark.org.tr/en/pub/ijaet

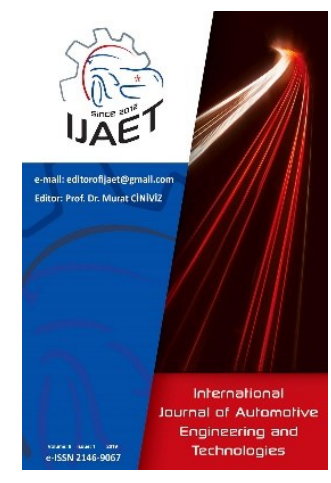

Original Research Article

\title{
The determination of effect of windshield inclination angle on drag coefficient of a bus model by CFD method
}

\author{
Cihan Bayındırlı ${ }^{*}$, Mehmet Çelik ${ }^{2}$ \\ $1,{ }^{*}$ Nigde Vocational School of Technical Sciences, Nigde Omer Halisdemir University, 51200 Nigde, Turkey \\ ${ }^{2}$, Engineering Faculty, Karabuk University, 78050, Karabük, Turkey
}

\section{ARTICLE INFO}

1 0000-0001-9199-9670

2 0000-0002-3390-1716

* Corresponding author cbayindirli@ohu.edu.tr

Received: Apr 20, 2020

Accepted: June 2, 2020

Published by Editorial Board Members of IJAET

(C) This article is distributed by Turk Journal Park System under the CC 4.0 terms and conditions.

\begin{abstract}
This paper focuses on determining of windshield inclination angle to aerodynamic drag coefficient for a 1/64 scaled bus model by Computational Fluid Dynamics (CFD) method. The bus models were designed by using SolidWorks program in 4 different windshield inclination angle $\left(\alpha=0^{\circ}, \alpha=15^{\circ}, \alpha=30^{\circ}, \alpha=45^{\circ}\right)$. Flow analysis were performed at $15 \mathrm{~m} / \mathrm{s}, 20 \mathrm{~m} / \mathrm{s}, 25 \mathrm{~m} / \mathrm{s}$ and $30 \mathrm{~m} / \mathrm{s}$ free flow velocities and between the range of 173000-346000 Reynolds numbers in Fluent $\AA$ program. To provide geometric similarity $1 / 64$ scaled licensed model bus was used in order to obtain drawing datas. The blockage rate was $3.39 \%$ for the kinematic similarity. Reynolds number independence was used to ensure dynamic similarity in study. The effect of windshield inclination angle to drag coefficient was determined by CFD method. The aerodynamic drag coefficients $\left(C_{D}\right)$ of the bus models were determined as 0.759 for model $1,0.731$ for model 2, 0.683 for model 3 and 0.623 for model 4 . There are $17.92 \%, 14.84 \%$ and $8.76 \%$ drag reduction in model 4 which has $\alpha=45^{\circ}$ windshield inclination angle when compared model $1\left(\alpha=0^{\circ}\right)$, model $2\left(\alpha=15^{\circ}\right)$ and model $3\left(\alpha=30^{\circ}\right)$ respectively. $0.4 \%$ drag reduction was obtained by increasing every 1 degree of windshield angle. The windshield inclination angle considerably affects drag forces on buses. The distribution of total drag was determined as pressure-friction based. The flow visualizations were obtained and flow structure around of bus models was detected.
\end{abstract}

Keywords: Aerodynamic, drag coefficient, windshield inclination angle, bus model, CFD

\section{Introduction}

The flow structure around of vehicles and aerodynamic drag forces significantly affect the performance of vehicle's fuel consumption, acceleration, way handling, exhaust emissions, noise and comfort. The drag force increases proportionally with the square of the speed. Therefore, most of the engine power spends to beat the aerodynamic drag force in high vehicle speed. One of the main subjects of automotive industry is to get better the aerodynamics of vehicle design in order to diminish the drag coefficient. So CFD is used to determine drag forces and flow structure around of vehicles. It provides significant advantage in terms of time and cost. There are many academic studies in literature in order to investigate of flow structure around of vehicles or decreasing drag coefficient of vehicles. Some study summaries in literature were given below. 
A car geometry was modified to decrease drag force. Rear under body diffuser and vortex generator were used in study. Body diffuser can reduce the drag by $6.14 \%$ and vortex generator can reduce the drag by $2.28 \%$ [1]. The effect of front and rear windscreen angles of a car on the drag force was investigated in a study. The aerodynamic behavior of the car was studied with different front and rear windscreen angles. They tried to estimate an optimal shape for the car based on the least drag coefficient. Consequently, an optimal car shape was proposed by improving the car's aerodynamic design including the surface roughness and windscreen angles. The drag coefficient was decreased by $8.88 \%$ compared to the initial design. This would offer a significant opportunity for reducing the fuel consumption [2]. The drag coefficient of $1 / 15$ scale minibus model was minimized by NACA 2415 airfoil structured vortex generator and front spoiler in Fluent [3]. The drag coefficient of base minibus model was 0.415 . The $\mathrm{C}_{\mathrm{D}}$ coefficient of the model minibus was decreased $10.94 \%$ with original designed NACA 2415 airfoil structured vortex generator in model $1.22 .59 \%$ drag reduction was obtained by designed front spoiler. The effect of this drag reduction on fuel consumption about $6-12 \%$ at high vehicle speeds. Most of the usable energy from the engine uses to overcoming the aerodynamic drag (53\%) and rolling resistance (32\%); only $9 \%$ is required for auxiliary equipment and $6 \%$ is used by the drive-train. $15 \%$ reduction in aerodynamic drag at highway speed of $55 \mathrm{mph}$ can result in about $5-7 \%$ in fuel saving [4]. The flow structure around a bus model was examined by using the CFD method. Three models were developed to reduce the drag force of the bus model. They achieved an aerodynamic improvement as respectively $6.57 \%, \quad 25.82 \%$ and $24.42 \%$ [5]. The aerodynamic drag of a semi-trailer truck was reduced optimization of rear height according to the standard model. It was observed that vehicle aerodynamic drag may decrease by up to $9.1 \%$. It shows that $4.7 \%$ improvement can obtain in fuel consumption [6]. The drag coefficient of a car model was reduced from 0.41 to 0.22 by using flow control method [7]. The lift and drag forces of a square prism with a (splitter) plate experimentally investigated. Drag coefficient at $0^{\circ}$ is obtained as 2.02 for the square prism alone, and 1.04 for the square cylinder with splitter plate. Maximum drag reduction for the square cylinder with the plate is $50 \%$ as compared to the square cylinder at $0^{\circ}$ and $15^{\circ}$ [8]. The effects of grilles on the aerodynamic drag coefficient and energy loss was investigated in a study. For this purpose, grilles have been placed horizontally to the front of the vehicle. Firstly, the aerodynamic drag coefficient and aerodynamic energy loss of the vehicle model without grilles have been determined numerically. The effect of the grilles placed in the front of vehicle on aerodynamic drag and energy loss compared to the vehicle model without grilles [9]. The flow structure around the Ahmed body model numerically investigated. They reduced the drag coefficient by $13.34 \%$. by using redirector plate [10]. Yagiz, et al. reduced the total aerodynamic drag coefficient of an air vehicle by $5.03 \%$ using the active and passive flow control methods on in the case of transonic flight [11]. The drag coefficient of Mercedes Travego bus was calculated as 0.698 using CFD method. They obtained $38.7 \%$ drag reduction by passive flow control methods when compared to the base model [12].

The aim of this study determination of effect of windshield inclination angles on drag coefficient in a bus model. Determination of the optimum windscreen angle of a bus model by numerical method is the original part of this study. This paper also includes examine the flow structure around the bus model, determine zones on bus model which form high aerodynamic drag. Flow separations and distribution of total drag force as pressure and friction on the bus model were determined by numerical flow analysis.

\section{Material Methods}

The aerodynamic specifications of base bus model (Model 4, $\alpha=45^{\circ}$ ) were determined in a study [13]. The drawing data of bus models were given in Fig.1.

\subsection{Similarity conditions}

Both experimental and numerical studies in aerodynamic, three similarity conditions have to provide between prototype and model vehicles. These are geometric, kinematic and dynamic similarity conditions. 


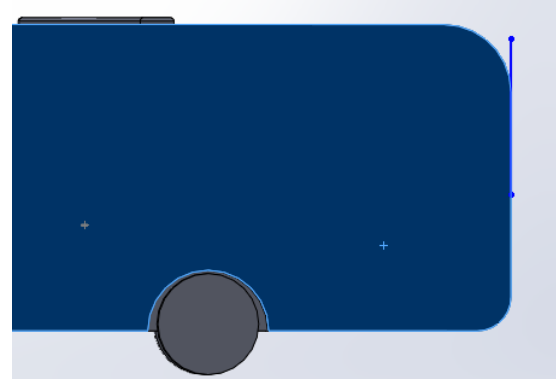

$\left(\alpha=0^{\circ}\right)$

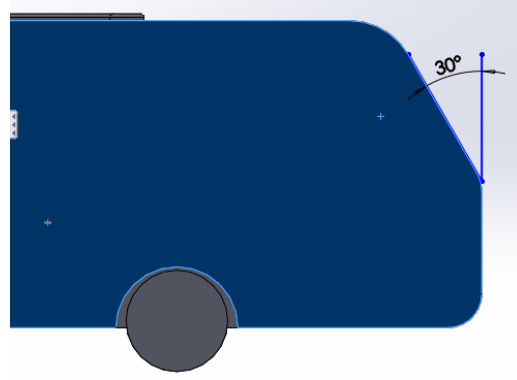

$\left(\alpha=30^{\circ}\right)$

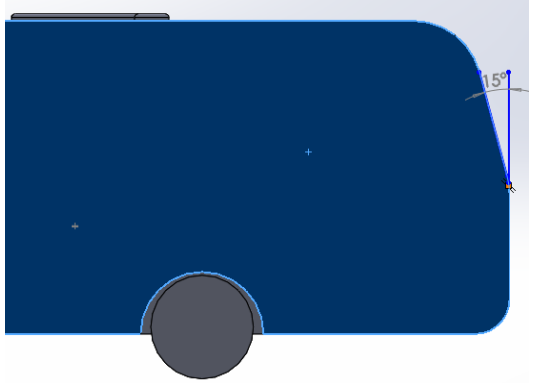

$\left(\alpha=15^{\circ}\right)$

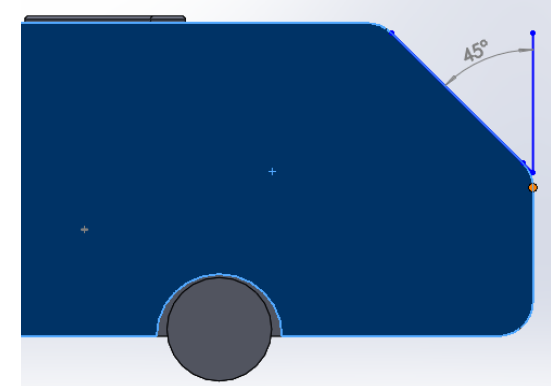

$\left(\alpha=45^{\circ}\right)$

Fig. 1. SolidWorks drawings of bus models

To provide geometric similarity, a licensed model bus was used in analysis. To provide kinematic similarity blockage rate must be less than a critic value. The front surface area of model bus is $0.00542 \mathrm{~m}^{2}$; front surface area of test area is $0.16 \mathrm{~m}^{2}$ and blockage rate is $3.39 \%$. The blocking rate should be lower than $7.5 \%$ in literature [14]. It is very difficult providing of real driving conditions in aerodynamic studies. It can be providing real wind tunnel sizes with prototype vehicle. So Reynolds number independence was used to provide dynamic similarity in the study. This method provides great advantage in aerodynamic studies.

\subsection{Numerical algorithm}

The solution proceeds of numerical flow analysis were given as below by the following steps;

Firstly, drawing geometries of bus models were drawn by Computes Aided Design (CAD) in SolidWorks ${ }^{\circledR}$ program. The drawing datas were saved as "Step" file and transferred to meshing domain. As seen in Fig. 2 the grid was formed more frequently in the regions which significantly affects the aerodynamic structure of the model bus. The boundary definitions were defined as inlet, outlet, wall, road and vehicle model. Then the mesh file was forwarded to the setup section. The pressure-based solver type, absolute velocity formulation and steady flow were used in analysis. The air was used as fluid and its density and viscosity and boundary conditions were defined to solver. The setup values were initialized and calculations were started. The convergence criteria and the iteration number were fallowed in graphic. The adaptive grid method was used to obtain true solution in numerical flow analysis. Drag force, drag coefficient was calculated and flow visualizations were gained.

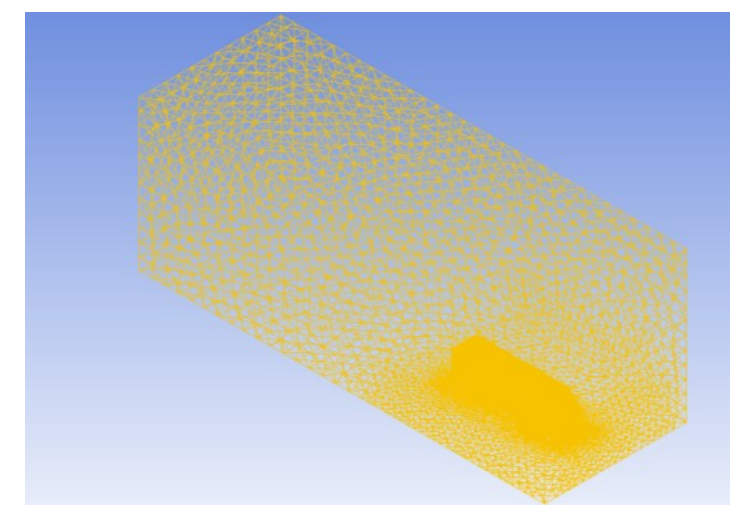

Fig.2. Mesh distribution on bus model

\subsection{Adaptive grid method in mesh strategy}

The using of adaptive grid method to obtain true solution in numerical flow analysis has big advantages. The aim of this method is to increase of solution accuracy by providing dynamic refinement. H-refinement was used to obtain better mesh quality by increasing the total number of grid elements (parent to child cells) within a base grid. This technique, known as mesh enrichment or refinement, modifies the grid at regions where worse mesh structure available. Frequently, the method carries out by 
subdividing grid elements into smaller components. The modification of mesh resolution by changing the mesh connectivity. The simplest strategy for this type of refinement subdivides cells, while more complex procedures may insert or remove nodes (or cells) to change the overall mesh topology. In the subdivision case, every bigger cells were divided into smaller cells [3].

For the model buses, between the numbers of 1030562-2082089 triangular volumes cell structure (tedrahedrons) were formed at first. Adaptive mesh technique was used for better mesh distribution in every 100 iterations. Mesh numbers were given in Table 1. After 6th adaptive mesh application 11615182 mesh number were formed in solution volume. In 6th adaptive application, desired convergence was obtained and solving was stopped. Mesh refinement views in of 1 th adaptive application was given in Fig. 3.

Table 1. Mesh refinement values after 6. Adaptive

\begin{tabular}{cccc}
\hline $\begin{array}{c}\text { Number of } \\
\text { adaptive }\end{array}$ & $\begin{array}{c}\text { Original } \\
\text { cells }\end{array}$ & Adapted & Change \\
\hline 6. Adaptive & 9541488 & 11615182 & 2073694 \\
\hline
\end{tabular}

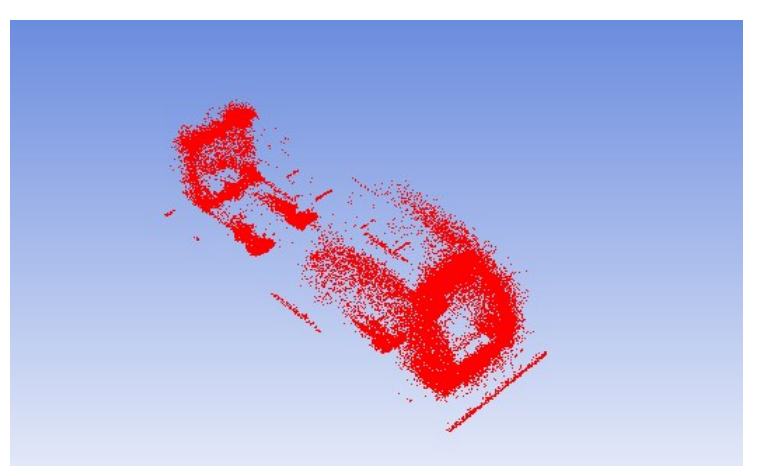

Fig. 3. Mesh refinement in solution domain of model 1 bus after 1 th adaptive

\subsection{Governing equations}

The Fluent ${ }^{\circledR}$ package program solves general integral equations for continuity, momentum, energy, turbulence using finite volume method. In study, convergence criteria are taken as $1.0 \times 10^{-3}$ for continuity, $\mathrm{x}$-velocity, $\mathrm{y}$-velocity and z-velocity. The turbulence intensity was taken as $1 \%$. The air density is $1 \mathrm{~kg} / \mathrm{m}^{3}$ and the dynamic viscosity is $1.56 \times 10^{-5}$ were defined. The front surface area of the vehicle is calculated as $0.00542 \mathrm{~m}^{2}$. The numeric flow analysis were carried out using a Workstation computer.

There are two important equations of solving of flow by differential equations. These are equations of continuity and momentum (NavierStokes). In this approach, the density is constant, which provides a significant advantage in the use of the CFD method. There are 4 unknowns value in the differential solution of the flow. These are pressure and the 3 components of free flow velocity in 3D flow. The continuity equation is expressed as the mass balance in the control volume in a flow.

$\frac{\partial \rho}{\partial t}+\frac{\partial(\rho u)}{\partial x}+\frac{\partial(\rho v)}{\partial y}+\frac{\partial(\rho w)}{\partial z}=0$

Navier - Stokes and continuity equations are also referred to as differential motion equations. When these equations are solved, some assumptions are taken and pressure and three components of velocity $(\mathrm{x}, \mathrm{y}, \mathrm{z})$ were calculated [15].

$$
\begin{aligned}
& \rho\left(\frac{\partial u}{\partial t}+u \frac{\partial u}{\partial x}+v \frac{\partial u}{\partial y}+w \frac{\partial u}{\partial z}\right)=-\frac{\partial p}{\partial x}+\rho g_{x}+\mu\left(\frac{\partial u^{2}}{\partial x^{2}}+\frac{\partial u^{2}}{\partial y^{2}}+\frac{\partial u^{2}}{\partial z^{2}}\right) \\
& \rho\left(\frac{\partial v}{\partial t}+u \frac{\partial v}{\partial x}+v \frac{\partial v}{\partial y}+w \frac{\partial v}{\partial z}\right)=-\frac{\partial p}{\partial y}+\rho g_{y}+\mu\left(\frac{\partial v^{2}}{\partial x^{2}}+\frac{\partial v^{2}}{\partial y^{2}}+\frac{\partial v^{2}}{\partial z^{2}}\right) \\
& \rho\left(\frac{\partial w}{\partial t}+u \frac{\partial w}{\partial x}+v \frac{\partial w}{\partial y}+w \frac{\partial w}{\partial z}\right)=-\frac{\partial p}{\partial z}+\rho g_{z}+\mu\left(\frac{\partial w^{2}}{\partial x^{2}}+\frac{\partial w^{2}}{\partial y^{2}}+\frac{\partial w^{2}}{\partial z^{2}}\right)
\end{aligned}
$$

The drag coefficient $\left(C_{D}\right)$ is the function of the drag force $F_{D}$, density $\rho$, free flow velocity $V$ and front view area and it is given in Eq. (5).

$$
\mathrm{C}_{\mathrm{D}}=\frac{F_{D}}{1 / 2 \rho \mathrm{V}^{2} \mathrm{~A}}
$$

\subsection{Mesh independency in CFD analysis}

In this study adaptive grid refinement method was used to obtain desired mesh quality. Moreover, a grid independence study was made in order to guarantee the results does not affect from element size and quality. Related results and graph were given in Fig. 4.

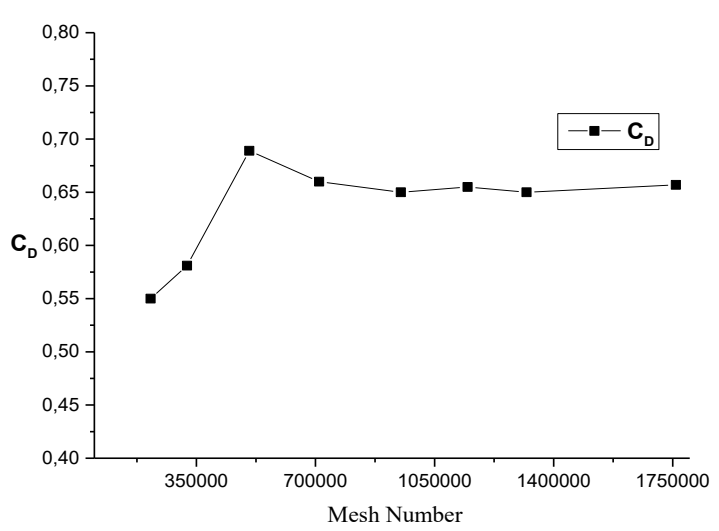

Fig. 4. Mesh independency graph [13] 


\section{CFD Results}

\subsection{The drag coefficient of model 1 bus $\left(\alpha=0^{\circ}\right)$}

As seen in Table 2, the drag coefficient of model 1 was obtained average 0.759 as a result of 4 different flow analysis. The total drag coefficient occurs from $87.15 \%$ pressure based and $12.85 \%$ friction based. Flow visualizations around of model 1 bus were given Fig. 5-6.

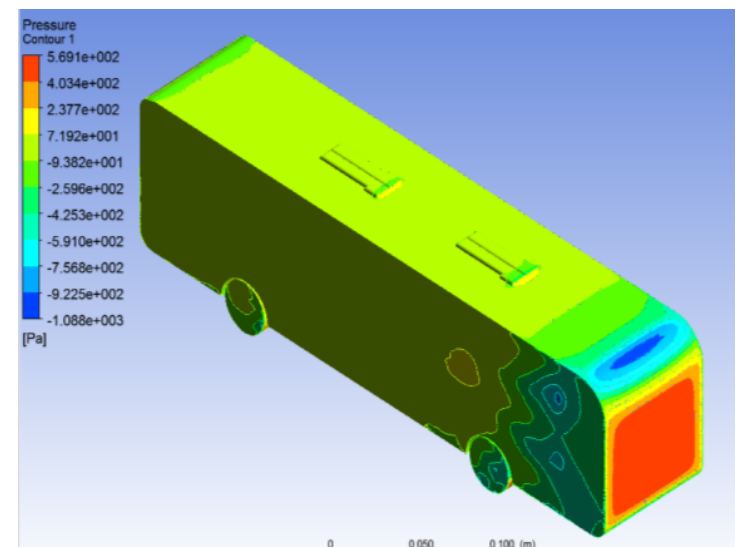

Fig. 5. Pressure distribution on the model 1

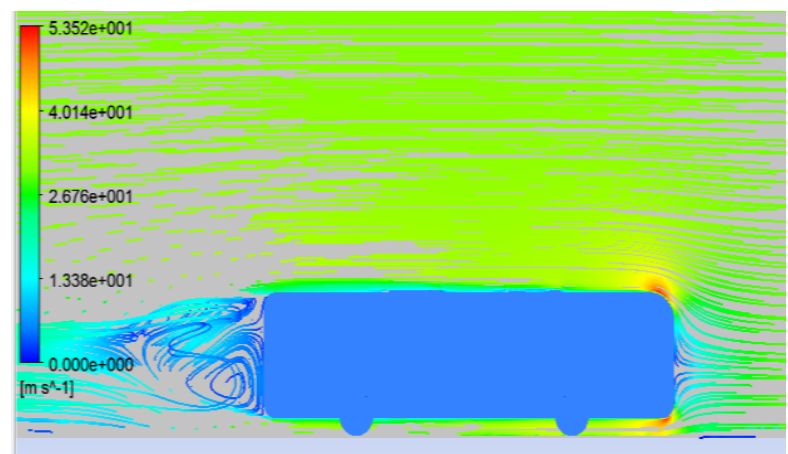

Fig.6. Streamline image around of model 1

\subsection{The drag coefficient of model 2 bus $\left(\alpha=15^{\circ}\right)$}

As seen in Table 3, the $C_{D}$ coefficient of the model 2 bus was calculated as 0.731 in average. When compared model 1 bus which has $\alpha=0^{\circ}$ windshield inclination angle there is $3.62 \%$ drag coefficient reduction. Pressure distribution on bus model and streamline image of model 2 bus were given Fig. 7-8.

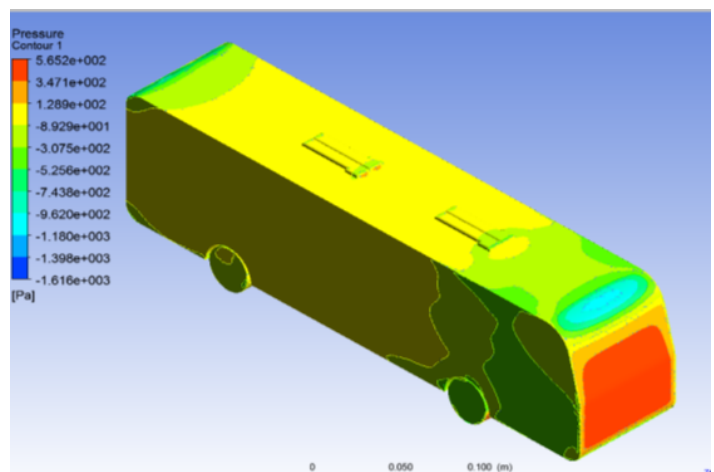

Fig. 7. Pressure distribution on the model 2

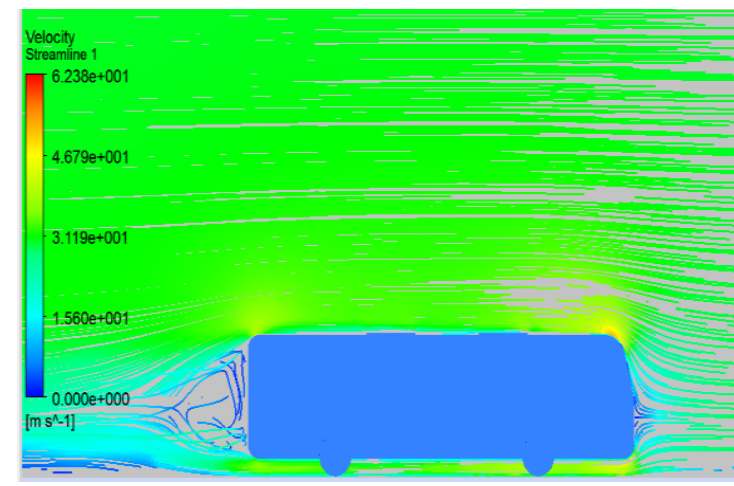

Fig.8. Streamline image around of model 1

Table 2. Aerodynamic drag coefficients of model 1 bus

\begin{tabular}{|c|c|c|c|c|}
\hline $\begin{array}{c}\text { Free Flow } \\
\text { Velocity }(\mathbf{m} / \mathbf{s})\end{array}$ & $\begin{array}{c}\text { Reynolds } \\
\text { Number }\end{array}$ & $\begin{array}{c}\text { Pressure } \\
\text { Based Drag } \\
\text { coefficient }\end{array}$ & $\begin{array}{c}\text { Friction } \\
\text { Based Drag } \\
\text { Coefficient }\end{array}$ & $\begin{array}{c}\text { Total } \\
\text { Drag } \\
\text { Coefficient }\end{array}$ \\
\hline 15 & 173077 & 0.644 & 0.116 & 0.760 \\
\hline 20 & 230769 & 0.686 & 0.098 & 0.784 \\
\hline 25 & 288462 & 0.663 & 0.091 & 0.754 \\
\hline 30 & 346154 & 0.653 & 0.084 & 0.737 \\
\hline \multicolumn{2}{|c|}{ Average } & 0.661 & 0.097 & 0.759 \\
\hline \multicolumn{5}{|c|}{ Table 3. Aerodynamic drag coefficients of model 2 bus } \\
\hline $\begin{array}{c}\text { Free Flow } \\
\text { Velocity }(\mathrm{m} / \mathrm{s})\end{array}$ & $\begin{array}{l}\text { Reynolds } \\
\text { Number }\end{array}$ & $\begin{array}{c}\text { Pressure } \\
\text { Based Drag } \\
\text { coefficient }\end{array}$ & $\begin{array}{c}\text { Friction } \\
\text { Based Drag } \\
\text { Coefficient }\end{array}$ & $\begin{array}{c}\text { Total } \\
\text { Drag } \\
\text { Coefficient } \\
\end{array}$ \\
\hline 15 & 173077 & 0.617 & 0.098 & 0.715 \\
\hline 20 & 230769 & 0.672 & 0.068 & 0.740 \\
\hline 25 & 288462 & 0.646 & 0.077 & 0.723 \\
\hline 30 & 346154 & 0.684 & 0.064 & 0.748 \\
\hline \multicolumn{2}{|c|}{ Average } & 0.655 & 0.077 & 0.731 \\
\hline
\end{tabular}


Table 4. Aerodynamic drag coefficients of model 3 bus

\begin{tabular}{ccccc}
\hline $\begin{array}{c}\text { Free Flow } \\
\text { Velocity (m/s) }\end{array}$ & $\begin{array}{c}\text { Reynolds } \\
\text { Number }\end{array}$ & $\begin{array}{c}\text { Pressure Based Drag } \\
\text { coefficient }\end{array}$ & $\begin{array}{c}\text { Friction Based Drag } \\
\text { Coefficient }\end{array}$ & $\begin{array}{c}\text { Total Drag } \\
\text { Coefficient }\end{array}$ \\
\hline 15 & 173077 & 0.610 & 0.076 & 0.686 \\
20 & 230769 & 0.613 & 0.074 & 0.687 \\
25 & 288462 & 0.603 & 0.073 & 0.676 \\
30 & 346154 & 0.599 & 0.083 & 0.681 \\
& Average & & $\mathbf{0 . 6 0 6}$ & $\mathbf{0 . 0 7 6}$ \\
\hline Free Flow & Reynolds & Pressure Based & Friction Based Drag & Total Drag \\
Velocity (m/s) & Number & Drag coefficient & Coefficient & Coefficient \\
\hline 15 & 173077 & 0.536 & 0.094 & 0.630 \\
20 & 230769 & 0.537 & 0.086 & 0.623 \\
25 & 288462 & 0.545 & 0.072 & 0.617 \\
30 & 346154 & 0.545 & 0.076 & 0.621 \\
& Average & $\mathbf{0 . 5 4 1}$ & $\mathbf{0 . 0 8 2}$ & $\mathbf{0 . 6 2 3}$ \\
\hline
\end{tabular}

\subsection{The drag coefficient of model 3 bus} $\left(\alpha=30^{\circ}\right)$

Aerodynamic drag coefficient of the model 3 bus was obtained as 0.683 . There are $6.67 \% \mathrm{drag}$ reduction when compared model 2 bus $\left(\alpha=15^{\circ}\right)$ and $10.05 \%$ with model 1 bus $\left(\alpha=0^{\circ}\right)$. These results support model 1 bus results. As windshield inclination angle increase drag coefficient decrease. Test results and flow visualizations were shown in Table 4, in Fig. 910 .

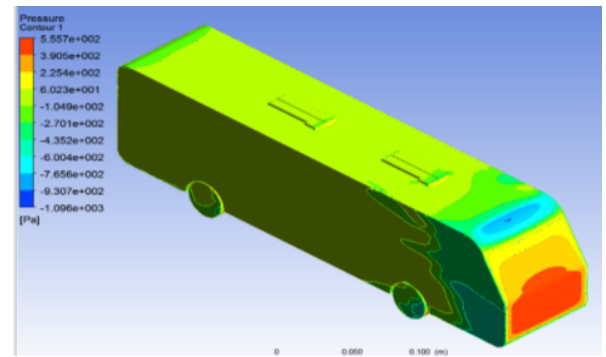

Fig. 9. Pressure distribution on the model 3

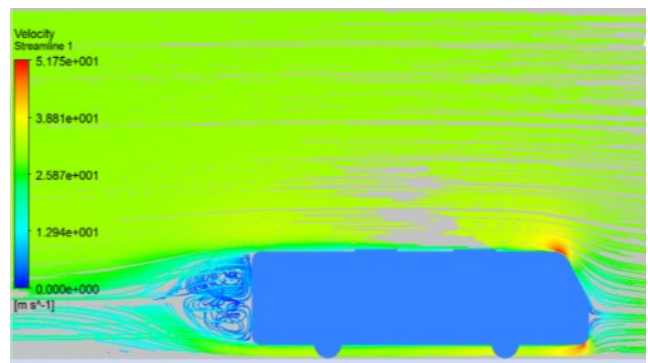

Fig. 10. Streamline image around of model 3

\subsection{The drag coefficient of model 4 bus $\left(\alpha=45^{\circ}\right)$}

The drag coefficient values of model 4 bus were given in Table 5. Average drag coefficient of model 4 bus was determined 0.623 . These values coherent with real bus drag coefficient values.

As seen in this study windshield inclination angle considerably affect drag forces in buses. There are $17.92 \%, 14.84 \%$ and $8.76 \%$ drag reduction when compared model $1\left(\alpha=0^{\circ}\right)$, model $2\left(\alpha=15^{\circ}\right)$ and model $3\left(\alpha=30^{\circ}\right)$ respectively. The total drag force of model 4 occurs from $86.80 \%$ pressure based and $13.20 \%$ friction based. Flow visualitions were given in Fig. 11-12.

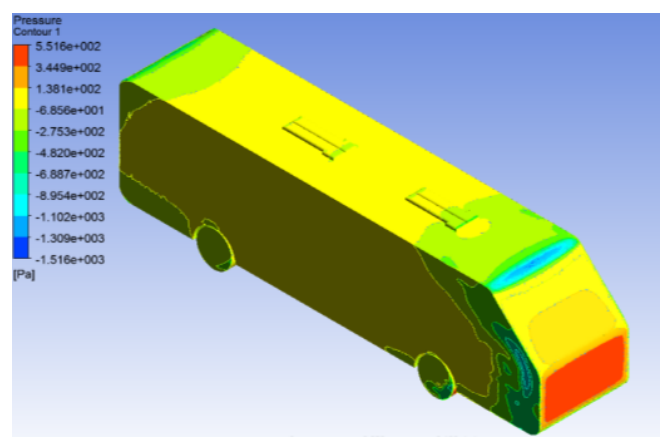

Fig. 11. Pressure distribution on the model 4

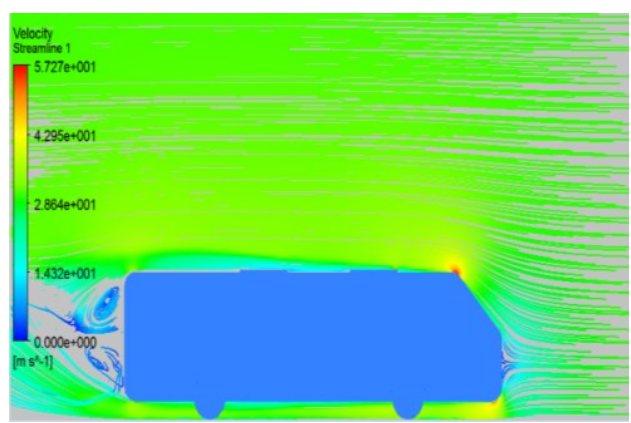

Fig. 12. Streamline image around of model 4 
The drag force increases proportionally with the square of the vehicle speed. When drag coefficient of vehicle decreases $2 \%$, fuel consumption decreases about $1 \%$ in high speeds. Buses perform cruising at high speeds in intercity or between the countries. So the aerodynamic shape and design of a buses important in fuel consumption and travelling costs. The vehicle moves to forward by power of engine. There are reverse forces to vehicle movement. The biggest reverse force component is aerodynamic force. The other reverse forces are rolling, ramping and acceleration forces. Reducing aerodynamic force is efficiency of engine power and therefore in fuel consumption $[16,17]$. As a result of flow analysis as windshield inclination angle increased drag coefficient decreased. For the ground vehicles, big percent of total drag force is pressure based which is seen in this study also. As seen in Fig. 13 the lowest $C_{D}$ value obtained in model 4 which has biggest windshield inclination angle.

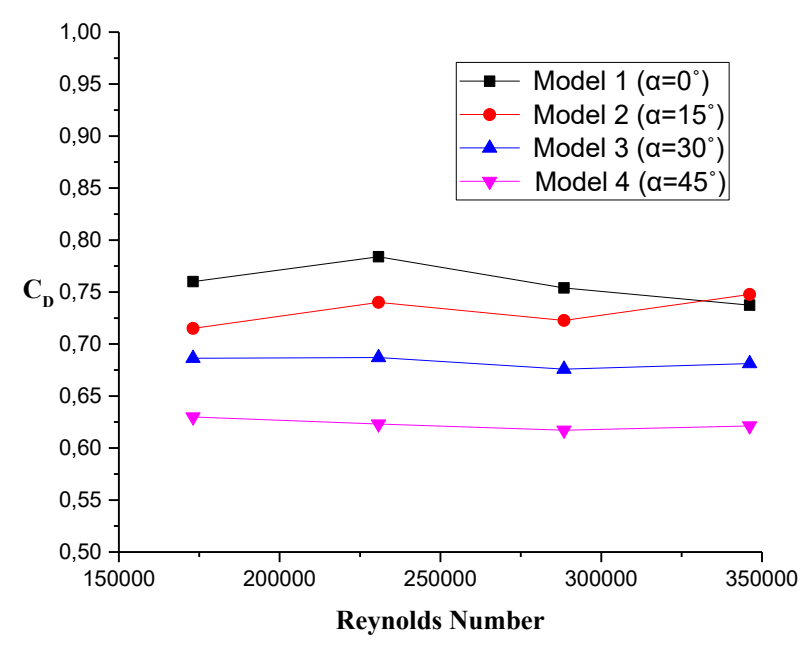

Fig.13. The graph of $C_{D}$ values of model buses

As seen in flow visualizations there are big areas on front of bus model where stagnation pressure occurs. Because most area of the front of the bus is perpendicular to the flow. In model 1 about all front surface of bus perpendicular to the flow. So flow crashes on front surface of bus (bumper and windshield) and stops. It makes big pressure based drag force. When windshield inclination angle increased the geometry of bus model had more aerodynamic shape. So flow structure was improved by inclination angle and pressure based drag force decreased. The source of drag coefficient minimization of model buses is this. The same result was obtained in a thesis study with increasing windshield attack angle drag coefficient decreases on a commercial vehicle [18].

\section{Conclusions}

In this study the flow structure around of 4 different bus models were examined numerically. The effect of windshield inclination angle to drag coefficient was determined by CFD method. As seen in this study windshield inclination angle considerably affect drag forces on buses. $17.92 \%, 14.84 \%$ and $8.76 \%$ drag reduction was obtained in model 4 which has $\alpha=45^{\circ}$ windshield inclination angle when compared model $1\left(\alpha=0^{\circ}\right)$, model 2 $\left(\alpha=15^{\circ}\right)$ and model $3\left(\alpha=30^{\circ}\right)$ respectively. Increasing of every 1 degree of windshield angle decreased to drag coefficient about $0.4 \%$. The aerodynamic drag force of a road vehicles is responsible for about $50 \%$ fuel consumption and at high vehicle speeds. This study shows that design of buse windshields with inclination angle so important for its performance and fuel consumption. In addition, the inclined design of the windshields to a certain limit does not affect the transport volume of the bus. Because this region is in a place to be characterized as dead volume.

\section{References}

1. Al Saadi, S. M. F., Aerodynamic Characteristics of Peugeot 405 Car Model. M. S. Thesis. University of Baghdad. Baghdad, Iraq, 2017.

2. Elrewami, M., and Aburawey I. The effect of front and rear windscreen angles on the aerodynamic drag force of a simplified car model. International Journal of Energy Applications and Technologies 6-3, 83-88, 2019.

3. Bayindirli, C. Numerical Drag Reduction Of A Ground Vehicle By Naca2415 Airfoil Structured Vortex Generator And Spoiler, International Journal of Automotive Technology, 20-5, 943-948, 2019.

4. Bellman, M. Agarwal, R. Naber, J. and Chusak, L. Reducing energy consumption of ground vehicles by active flow control. In ASME 2010 4th International Conference on Energy Sustainability. pp 785-793, 2010.

5. Patil, C.N. Shashishekar, K.S. Balasubramanian, A.K. Subbaramaiah, S.V. 
Aerodynamic Study and drag coefficient optimization of passenger vehicle, International Journal of gineering Research \& Technology (IJERT), 1-7, 1-8, 2012.

6. Kütük, E., Çalışkan, M. and Bayram, A. A Study on Aerodynamic Drag of Semi-Trailer Truck with Different Rear Height. Journal of Current Researches on Engineering, Science and Technology, 4-2, 113-124, 2018.

7. Pal, S. S., and Singh, A. Design and simulate an aerodynamic car body for the Maruti Suzuki 800 with less coefficient of drag. Int. Research J. Engineering and Technology 36, 299-303, 2016.

8. Seyhan, M, Sarıoglu, M., and Akansu, Y.E. Effect of Attack Angle On Flow Around a Square Prism with A Splitter Plate. Uludağ University Journal of the Faculty of Engineering, 23-2, 233-240, 2018.

9. Yildiz, A., Dandil, B. Investigation of effect of vehicle grilles on aerodynamic energy loss and drag coefficient. Journal of Energy Systems, 2-4, 190-203, 2018.

10. Raina, A. and Khajuria, A. Flow Control Around a 3D-Bluff Body Using Passive Device. International Journal of Science and Engineering 4(1), 8-13, 2018.

11. Yagiz B. Kandil O. Pehlivanoglu Y.V. Drag minimization using active and passive flow control techniques. Aerospace Science and Technology 17, 21-31, 2012.

12. Mohamed, E.A. Radhwi, M.N. Abdel Gawad A.F. Computational investigation of aerodynamic characteristics and drag reduction of a bus model. American Journal of Aerospace Engineering 2(1-1), 64-73, 2015.

13. Bayindirli C., Çelik, M., Demiralp, M. The investigation of flow characteristic around a bus model by CFD method and improvement of drag force by passive flow control method. Journal of Polytechnic, 21-4, 785-795, 2018.

14. Çengel, Y. A., and Cimbala, J. M. Fundamentals of Fluid Mechanics and Applications. Güven Publish. İzmir, Turkey, 2008.

15. [15]. İnce, İ.T. Aerodynamic Analysis of GTD Model Administrative Service Vehicle PhD Thesis. Gazi Universty Institute of Science. Ankara. 30-66, 2010.

16. Wood, R.M., and Bauer, S.X.S. Simple and low cost aerodynamic drag reduction devices for tractor-trailer Trucks. SAE
Technical Paper, 01-3377, 1-18, 2003.

17. Özel, M., Aygün, E., Akansu, Y.E., Bayindirli, C., Seyhan, M. The passive flow control around a truck-trailer model. International Journal of Automotive Engineering and Technologies, 4-4,185 - 192, 2015.

18. Sarı, M.F. The Aerodynamic Analysis of Air Resistance Affecting the Front Form of Light Commercial Vehicles and Its Effect on Fuel Consumption, Osmangazi University, Institute of Science and Technology, Master Thesis, Eskişehir, 28-54, 2007. 